\title{
A new precipitation weighted method for determining the meteoric water line for hydrological applications demonstrated using Australian and global GNIP data
}

\author{
Catherine E. Hughes*, Jagoda Crawford \\ Australian Nuclear Science and Technology Organisation, Institute for Environmental Research, Locked Bag 2001 Kirrawee DC, NSW 2232, Australia
}

\section{A R T I C L E I N F O}

\section{Article history:}

Received 19 August 2011

Received in revised form 6 July 2012

Accepted 15 July 2012

Available online 24 July 2012

This manuscript was handled by

Konstantine P. Georgakakos, Editor-in-Chief,

with the assistance of Marco Borga,

Associate Editor

\section{Keywords:}

Deuterium

Oxygen-18

D-excess

Precipitation weighted meteoric water line Global Network of Isotopes in Precipitation (GNIP)

Australia

\begin{abstract}
S U M M A R Y
The relationship between $\delta^{2} \mathrm{H}$ and $\delta^{18} \mathrm{O}$ in precipitation at a site, known as the local meteoric water line (LMWL), is normally defined using an ordinary least squares regression (OLSR) which gives equal weighting to all data points regardless of the precipitation amount they represent. However, smaller precipitation amounts are more likely to have a lower D-excess due to re-evaporation of raindrops below the cloud-base or biases in the sampling method. In this paper we present an equation for a precipitation amount weighted least squares regression (PWLSR) that will correct these biases for use in groundwater and surface hydrology applications.

New LMWL equations are presented for Australian sites in the Global Network of Isotopes in Precipitation (GNIP), where the PWLSR consistently produces a LMWL with a larger gradient than the OLSR. Perth and Alice Springs exhibit the largest change in slope. This is consistent with the higher frequency of small monthly precipitation amounts with low D-excess values occurring at these sites in summer for Perth and throughout the year for Alice Springs.

The PWLSR method was also applied to 288 stations in the GNIP data base $(N>36)$ and the difference between the slopes of the LMWLs $\left(\Delta a=\right.$ slope $\left._{\mathrm{PWLR}}-\mathrm{Slope}_{\mathrm{OLSR}}\right)$ calculated for these stations. The mean change in slope, $\Delta a$ was 0.12 with $56 \%$ of sites showing an increase in slope or positive $\Delta a$ value and $44 \%$ having a decrease in slope or negative $\Delta a$. Sites with Mediterranean climates showed the greatest increase in slope. The magnitude of the change in slope followed some general trends showing a positive correlation with average $\delta^{2} \mathrm{H}$ and $\delta^{18} \mathrm{O}$ composition and rainfall variability, and negative correlation with period of record $(N)$.
\end{abstract}

Crown Copyright @ 2012 Published by Elsevier B.V. All rights reserved.

\section{Introduction}

Variations in the stable isotope composition of rainfall depend on many factors including seasonality, moisture source, rainfall amount and meteorological conditions during evaporation, condensation and precipitation. The relationship between $\delta^{2} \mathrm{H}$ and $\delta^{18} \mathrm{O}$ in precipitation is defined as a meteoric water line (MWL). Craig (1961) defined the first global meteoric water line (GMWL) to be $\delta^{2} \mathrm{H}=8 \cdot \delta^{18} \mathrm{O}+10$ using a least squares regression. Later efforts to define both global and local meteoric water lines (LMWLs) have often used arithmetic or weighted mean values on a monthly or annual time step or for the whole period of record (e.g. Rozanski et al., 1993). Alternative correlation equations used to define MWLs include the reduced major axis least squares regression (RMA) (IAEA, 1992) and the error-in-variables generalised least squared regression (Argiriou and Lykoudis, 2006).

\footnotetext{
* Corresponding author. Tel.: +61 297179366.

E-mail address: cath.hughes@ansto.gov.au (C.E. Hughes).
}

The Global Network of Isotopes in Precipitation (GNIP) (IAEA/ WMO, 2006) is the primary source of $\delta^{2} \mathrm{H}$ and $\delta^{18} \mathrm{O}$ data in precipitation globally. Local meteoric water lines based on GNIP or other data are used in a variety of hydrological applications, commonly to determine the relationship of surface or groundwaters to a potential precipitation source or to determine the degree of evaporative enrichment of the water. The intersection between the LMWL and a local evaporation line is commonly used as a start point for calculating evaporative enrichment.

The ordinary least squares regression (OLSR) widely used to determine the LMWL gives equal weighting to all data points regardless of the precipitation amount they represent. In reality smaller precipitation amounts are more likely to have a lower D-excess due to re-evaporation of raindrops below the cloud-base or biases in the sampling method. Larger precipitation events tend to be more depleted in the heavier isotopes for a number of reasons including more complete condensation of the vapour and lower exchange with surrounding vapour below the cloud (Dansgaard, 1964), and association of large events with particular synoptic patterns (Treble et al., 2005). In the study of precipitation processes 
the relationship between $\delta^{2} \mathrm{H}$ and $\delta^{18} \mathrm{O}$ is appropriately described by OLSR or RMA which fully considers the variability in D-excess. However, where the LMWL is used to interpret groundwater or surface water data the use of these regressions may introduce some unwanted effects. By allowing small precipitation amounts, which may have experienced evaporative enrichment, to have equal influence on the slope of the LMWL, an effect that is not in proportion to the hydrological significance of the precipitation is introduced. Whilst the use of weighted average or monthly values reduces this effect somewhat, it does not remove it. As a consequence, when analysing precipitation data some authors choose to exclude small rainfall events or low D-excess data in order to reduce their effect on their LMWL (e.g. Harvey, 2001). With higher frequency sampling becoming the norm, the variability in $\delta^{2} \mathrm{H}$ and $\delta^{18} \mathrm{O}$ values and precipitation amount for samples from a site increases, increasing the chance that more extreme values, that in the past would have been part of a composite, will influence calculated LMWLs. For applications of the LMWL relating to groundwater recharge, dam storage and major flow events, it is the higher precipitation events that are most important, so it is appropriate to use a LMWL that is weighted towards those events.

In this paper we present an equation for a precipitation amount weighted least squares regression (PWLSR) that will correct these biases. A precipitation amount weighted least squares regression is carried out on the monthly data from GNIP stations globally and the gradients of the resulting LMWLs are compared to those obtained from unweighted least squares methods currently in widespread use. Alternative LMWL parameters are presented and discussed in detail for Australian GNIP stations.

\section{Method}

Traditionally two methods have been used to determine the LMWL which is of the form $y=a x+b$ (IAEA, 1992); the ordinary least squares regression (OLSR) and the reduced major axis (RMA) regression, sometimes incorrectly called the orthogonal regression.

For the OLSR the slope of the line of best fit is given by:

$a=\frac{\sum x y-\frac{\sum x \sum y}{n}}{\sum x^{2}-\frac{\left(\sum x\right)^{2}}{n}}$

The intercept is given by:

$b=\frac{\sum y}{n}-a \frac{\sum x}{n}=\bar{y}-a \bar{x}$

The standard deviation of $a$ is given by

$\sigma_{a}=\frac{S_{y, x}}{\left(\sum x^{2}-\frac{\left(\sum x\right)^{2}}{n}\right)^{0.5}}$

where $S_{y, x}$ is the standard error of the estimate:

$S_{y, x}=\left[\frac{\sum y^{2}-b \sum y-a \sum x y}{n-2}\right]^{0.5}$

The standard deviation of $b$ is given by

$$
\sigma_{b}=S_{y, x}\left[\frac{\sum x^{2}}{n\left(\sum x^{2}-\frac{\left(\sum x\right)^{2}}{n}\right)}\right]^{0.5}
$$

For the RMA the slope of the line of best fit is given by:

$a=\frac{S_{y}}{S_{x}}=\left[\frac{\sum y^{2}-\frac{\left(\sum y\right)^{2}}{n}}{\sum x^{2}-\frac{\left(\sum x\right)^{2}}{n}}\right]^{0.5}$

The intercept is given by:

$b=\bar{y}-a \bar{x}$

\subsection{Precipitation weighted least squares regression (PWLSR)}

To reduce the effect of small precipitation samples on the calculation of the LMWL we propose the use of a precipitation amount weighted LMWL $\left(\delta^{2} \mathrm{H}=a \cdot \delta^{18} \mathrm{O}+b\right)$ for hydrological applications, where the parameters $a$ and $b$ in the line of best fit, $y_{i}=a x_{i}+b$, are obtained by minimising the least squares equation:

$L S=\frac{\sum_{i=1}^{n} p_{i}\left(y_{i}-a x_{i}-b\right)^{2}}{\sum_{i=1}^{n} p_{i}}$

From which the parameters $a$ and $b$ are determined by the following equations.

$$
\begin{aligned}
& a=\frac{\sum_{i=1}^{n} p_{i} y_{i} x_{i}-\frac{\sum_{i=1}^{n} p_{i} x_{i} \sum_{i=1}^{n} p_{i} y_{i}}{\sum p_{i}}}{\sum_{i=1}^{n} p_{i} x_{i}^{2}-\frac{\left(\sum_{i=1}^{n} p_{i} x_{i}\right)^{2}}{\sum p_{i}}} \\
& b=\frac{\sum_{i=1}^{n} p_{i} y_{i}-a \sum_{i=1}^{n} p_{i} x_{i}}{\sum p_{i}}
\end{aligned}
$$

The standard deviation of the parameters $a$ and $b$ are calculated as follows (adapted from IAEA (1992)):

$$
\begin{aligned}
& \sigma_{a w}=\frac{S_{y, x(w)}}{\left(\frac{n}{\sum p_{i}}\left(\sum p_{i} x_{i}^{2}-\frac{\left(\sum p_{i} x_{i}\right)^{2}}{\sum p_{i}}\right)\right)^{0.5}} \\
& \sigma_{b w}=S_{y, x(w)}\left[\frac{\sum p_{i} x_{i}^{2}}{n\left(\sum p_{i} x_{i}^{2}-\frac{\left(\sum p_{i} x_{i}\right)^{2}}{\sum p_{i}}\right)}\right]^{0.5} \\
& S_{y, x(w)}=\left[\frac{n}{n-2} \frac{\left(\sum p_{i} y_{i}^{2}-b \sum p_{i} y_{i}-a \sum p_{i} x_{i} y_{i}\right)}{\sum p_{i}}\right]^{0.5}
\end{aligned}
$$

The weighted correlation coefficient is given by:

$$
r_{w}^{2}=\frac{\left(\sum p_{i} x_{i} y_{i}-\frac{\sum p_{i} x_{i} \sum p_{i} y_{i}}{\sum p_{i}}\right)^{2}}{\left(\sum p_{i} x_{i}^{2}-\frac{\left(\sum p_{i} x_{i}\right)^{2}}{\sum p_{i}}\right)\left(\sum p_{i} y_{i}^{2}-\frac{\left(\sum p_{i} y_{i}\right)^{2}}{\sum p_{i}}\right)}
$$

For the statistical significance in the difference between the gradients of the un-weighted and weighted slopes the $t$-test, adopted from Volk (1958), is used.

\subsection{Location of Australian GNIP stations}

Australia has seven GNIP stations (Fig. 1 and Table 1) that have been operational continuously or intermittently since 1962 (excl. Cape Grim commencing in 1979) as part of the IAEA/WMO network. Statistics and historical background for these stations are presented by Liu et al. (2010). Six out of the seven stations are located close to the coast with the seventh, Alice Springs, being located in arid central Australia. The sample monthly precipitation amount against the month of year, for each station, is presented 


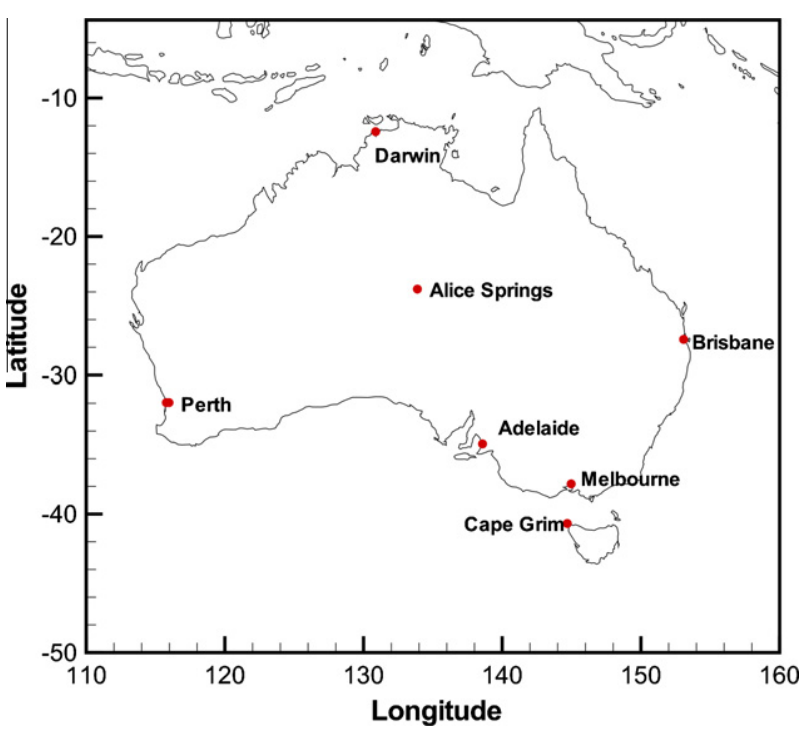

Fig. 1. Location of the Australian GNIP stations.

in Figs. 2c and 3c and in Supplementary data Figs. S1c-S5c. Also presented are the long term monthly minimum and maximum temperatures (obtained from http://www.bom.gov.au/climate/ data/). Note that the Perth and Perth CSIRO stations have been grouped together for this analysis.

Darwin shows a clear monsoon dominated seasonal cycle in the monthly rainfall totals with the highest frequency of large monthly rainfall amounts occurring in summer during the monsoon and very dry winters with little seasonal temperature fluctuation (Australian summer is December, January, February; winter is June, July, August). A strong seasonal cycle is also present in Perth with mostly small amounts of monthly precipitation in summer and the majority of rainfall occurring in the winter months. A larger precipitation amount in winter is also seen for Cape Grim and Adelaide, but not to the extent seen in Perth. Precipitation amount at all other stations is more consistent throughout the year. Alice Springs shows a large number of small monthly precipitation totals throughout the year. According to the Köppen-Geiger Climate Classification (Kottek et al., 2006) the classification for the Australian stations are; Darwin Aw (equatorial winter dry), Alice Springs BWh (hot arid desert), Brisbane Cfa (warm temperate fully humid with hot summers), Perth Csa (temperate warm with dry hot summer), Adelaide Csb (temperate warm dry warm summer), Melbourne and Cape Grim Cfb (warm temperate fully humid with warm summers).

Australian GNIP stations sample rainfall at 9 am daily from a standard unsealed rainfall collector, from which the water is poured into a larger bottle with a lid to create a composite sample which is collected monthly. This is according to the IAEA/WMO procedure (http://www-naweb.iaea.org/napc/ih/documents/ userupdate/sampling.pdf).

\section{Results and discussion}

The parameters of the fit and their errors for ordinary least squares regression (OLSR), reduced major axis regression (RMA) and precipitation weighted least squares regression (PWLSR), as well as the $t$-test significance of the difference in slope between the PWLSR and OLSR are presented for the entire GNIP dataset in the Supplementary data and in Table 1 for Australian sites.

LWMLs may be derived from amount weighted annual values rather than monthly values which provides a partial amount weighting to the outcome. We compared OLSR based on amount weighted annual average values from GNIP to the PWLSR based on monthly values and found that generally for sites with a long record the values had a moderate correlation $(r=0.57$ for 5 years or more of data, $N=242$ ), but for sites with less than 5 years of data the correlation was very poor $(r=0.21, N=73)$. Overall the range and standard deviation of slopes was much greater for the annual values and both the median and mean slope were greater (PWLSR Monthly: mean $=7.29 ;$ median $=7.5 ;$ SD $=0.81 ;$ IQ range $=0.97$. OLSR Annual: mean $=7.09 ;$ median $=7.36 ; \mathrm{SD}=3.42 ;$ IQ range $=7.94$ ). This is partially explained by the inclusion of sites with only a few years of data, where the annual regression is based on a small number of points which may be very close together. When monthly or higher frequency data is used the greater range and number of values results in a more sound definition of the slope. Therefore the use of a regression on annual weighted averages cannot be recommended over the use of a PWLSR on higher frequency data, particularly for short datasets.

\subsection{Australian GNIP stations}

For the Australian GNIP sites (Table 1) the PWLSR consistently produces a LMWL with a larger gradient than the OLSR. The difference between the slopes of the LMWLs calculated using the two different regression methods for each station is defined as $\Delta a$ ( $\Delta a=$ slope $_{\mathrm{PWLSR}^{-}}$slope $_{\mathrm{OLSR}}$ ). Alice Springs (Fig. 2) and Perth (Fig. 3) show the largest $\Delta a$, which is significant according to the $t$-test (Table 1). This is consistent with the higher frequency of small monthly precipitation amounts with low D-excess values occurring for small rainfall months in summer for Perth (Fig. 3b) and throughout the year for Alice Springs (Fig. 2b). Perth is well known for its highly seasonal rainfall, with $80-85 \%$ of rainfall falling in the cooler months from May to October (Fischer and Treble, 2008). Potential evaporation in the warmer months is substantial (Fischer and Treble, 2008, and references therein) increasing the likelihood of evaporative enrichment of raindrops beneath the

Table 1

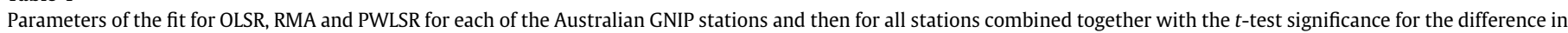
slope between the OLSR and PWLSR.

\begin{tabular}{|c|c|c|c|c|c|c|c|c|c|}
\hline \multirow{2}{*}{$\begin{array}{l}\text { Station } \\
\text { Station No. }\end{array}$} & \multirow[b]{2}{*}{$N$} & \multicolumn{2}{|l|}{ OLSR: } & \multicolumn{2}{|l|}{ RMA: } & \multicolumn{2}{|l|}{ PWLSR: } & \multirow[b]{2}{*}{$\Delta a$} & \multirow{2}{*}{$\begin{array}{l}T \text {-test } \\
\text { Significance }\end{array}$} \\
\hline & & $a \pm \sigma_{a}$ & $b \pm \sigma_{b}$ & $a \pm \sigma_{a}$ & $b \pm \sigma_{b}$ & $a \pm \sigma_{a}$ & $b \pm \sigma_{b}$ & & \\
\hline Darwin 9412000 & 222 & $7.55 \pm 0.12$ & $9.3 \pm 0.6$ & $7.74 \pm 0.11$ & $10.1 \pm 0.6$ & $7.74 \pm 0.12$ & $10.2 \pm 0.7$ & 0.19 & 0.24 \\
\hline Alice Springs 9432600 & 134 & $6.86 \pm 0.15$ & $4.5 \pm 0.8$ & $7.07 \pm 0.15$ & $5.1 \pm 0.8$ & $7.52 \pm 0.11$ & $9.3 \pm 0.9$ & 0.66 & 0.00 \\
\hline Brisbane 9457600 & 326 & $7.69 \pm 0.12$ & $12.5 \pm 0.5$ & $7.99 \pm 0.12$ & $13.6 \pm 0.5$ & $7.87 \pm 0.10$ & $12.8 \pm 0.5$ & 0.18 & 0.25 \\
\hline Perth 9460800/1 & 254 & $6.30 \pm 0.19$ & $7.5 \pm 0.7$ & $6.96 \pm 0.19$ & $9.8 \pm 0.7$ & $7.33 \pm 0.20$ & $13.1 \pm 0.8$ & 1.51 & 0.00 \\
\hline Adelaide 9467500 & 112 & $7.25 \pm 0.19$ & $7.9 \pm 0.8$ & $7.50 \pm 0.18$ & $8.9 \pm 0.8$ & $7.84 \pm 0.19$ & $10.7 \pm 0.9$ & 0.56 & 0.03 \\
\hline Melbourne 9486800 & 277 & $7.13 \pm 0.12$ & $7.0 \pm 0.6$ & $7.40 \pm 0.12$ & $8.2 \pm 0.6$ & $7.43 \pm 0.11$ & $8.6 \pm 0.6$ & 0.30 & 0.07 \\
\hline Cape Grim 9499801 & 200 & $6.26 \pm 0.13$ & $3.9 \pm 0.5$ & $6.52 \pm 0.13$ & $4.8 \pm 0.5$ & $6.56 \pm 0.14$ & $5.0 \pm 0.6$ & 0.30 & 0.13 \\
\hline All stations & 1525 & $7.12 \pm 0.05$ & $8.3 \pm 0.24$ & $7.43 \pm 0.05$ & $9.4 \pm 0.2$ & $7.60 \pm 0.05$ & $10.6 \pm 0.3$ & 0.48 & 0.00 \\
\hline Perth winter & 75 & $7.22 \pm 0.40$ & $13.8 \pm 1.6$ & $8.00 \pm 0.40$ & $16.9 \pm 1.6$ & $7.38 \pm 0.39$ & $14.2 \pm 1.6$ & 0.16 & 0.78 \\
\hline
\end{tabular}


(a)

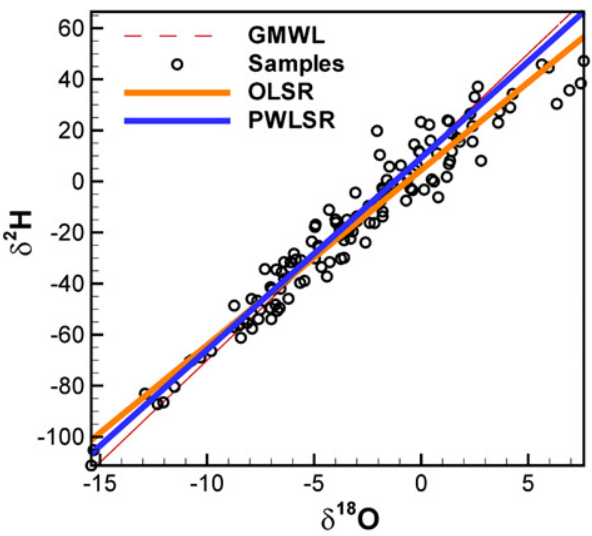

(c)

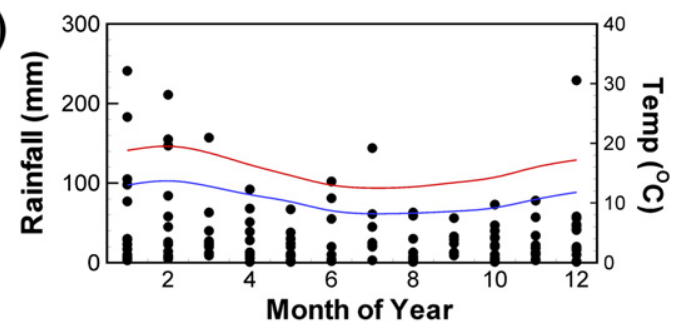

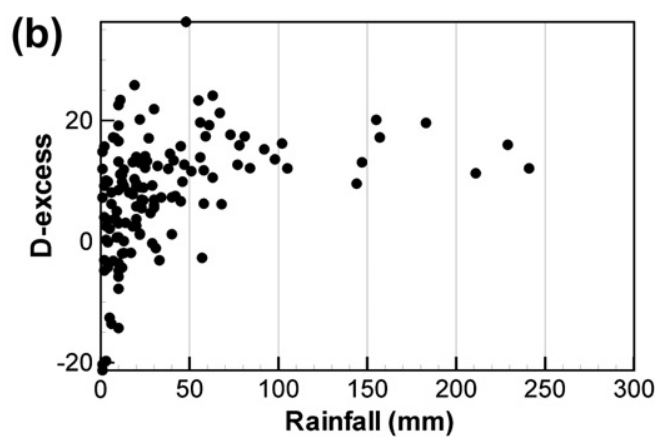

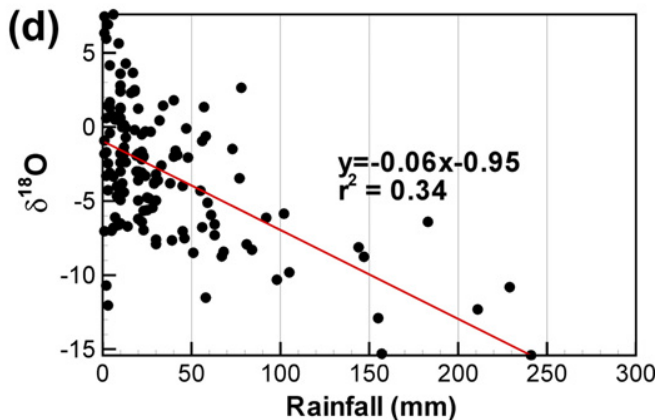

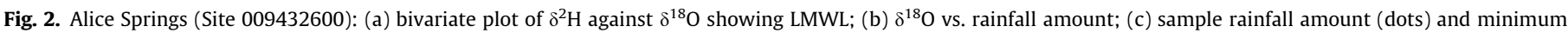

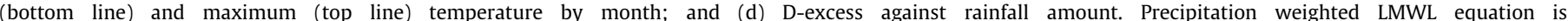
$\delta^{2} \mathrm{H}=7.52 \pm 0.11 \cdot \delta^{18} \mathrm{O}+9.3 \pm 0.9$.

(a)

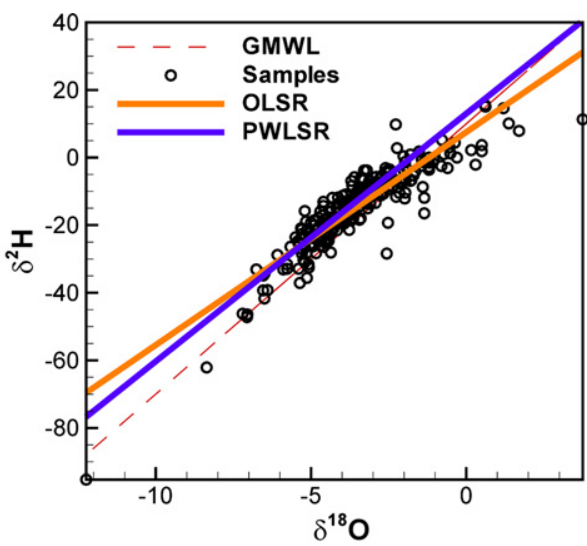

(c)

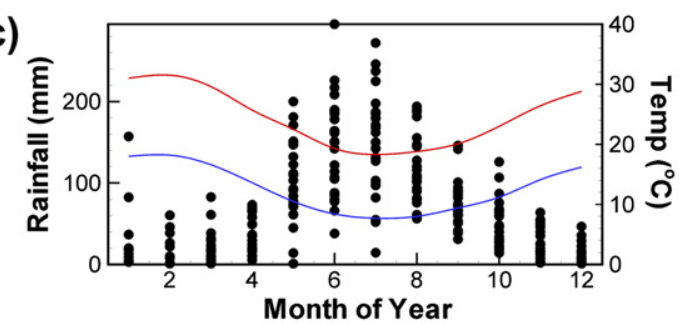

(b)

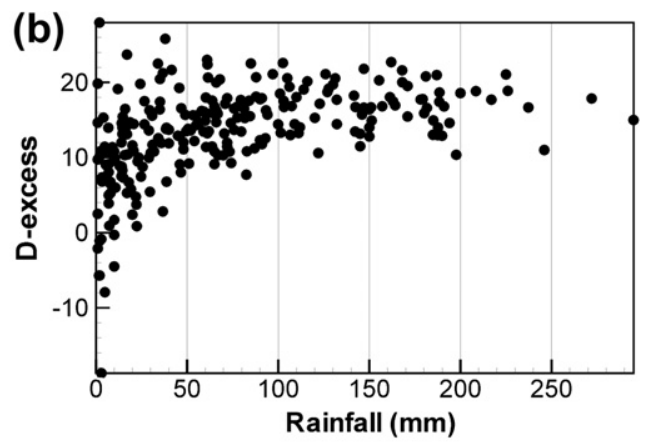

(d)

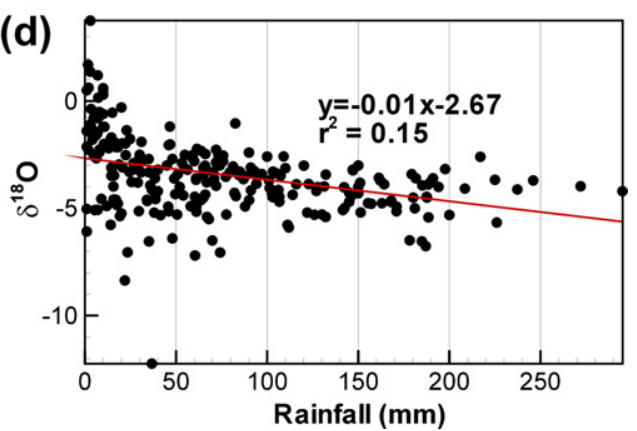

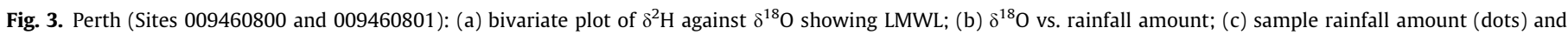

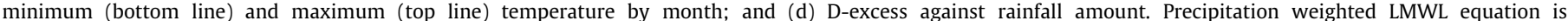
$\delta^{2} \mathrm{H}=7.33 \pm 0.20 \cdot \delta^{18} \mathrm{O}+13.0 \pm 0.8$.

cloud-base. When considering rainfall data for the winter months only (June, July and August), the LMWLs calculated using both the RMA and PWLSR methods were much closer and the difference or $\Delta a$ value is insignificant (last row of Table 1), indicating a strong influence of the low D-excess summer rainfall on the LMWL. The
RMA technique, which is appropriate when uncertainties are present in both the dependent and independent variables, in most cases results in a slope that is closer to that of PWLSR, as it minimises the triangular area between the measured points and the regression line (Carr, 2012). 
Darwin (Fig. S1) also exhibits highly seasonal rainfall due to the summer monsoon, however low D-excess values are not specifically associated with small rainfall amounts so the $\Delta a$ is small. The $\Delta a$ is also significant for Adelaide (Fig. S3) and Melbourne (Fig. S4) (at 97\% and 93\% confidence level, respectively), although, the difference between the slopes is less than that for Alice Springs and Perth. Perth and Alice Springs data show more variability in Dexcess around the LMWL whereas the other stations show values closer to the LMWL. Alice Springs is located in the interior arid region where high temperatures and low humidity mean that evaporation of raindrops beneath the cloud-base is likely to take place during small rainfall events. Small amounts of precipitation, particularly in low humidity conditions, are subject to sub-cloud evaporation of falling raindrops at any site, but this effect is more likely to be evident during dry summers in Perth, and to a lesser extent Adelaide and Cape Grim. In addition issues of evaporative fractionation induced during the sampling process are more likely to be evident in small precipitation amount samples.

The practice of excluding small rainfall events or low D-excess data is a subjective approach often considered when interpreting $\delta^{2} \mathrm{H}$ and $\delta^{18} \mathrm{O}$ data in precipitation. To demonstrate the subjectivity of such an approach, LMWLs were constructed using the OLSR method on the Alice Springs and Perth data after removing rainfall samples with a D-excess of less than 3\%o (the D-excess for evaporating ocean water at $20-30{ }^{\circ} \mathrm{C}$ and $95 \%$ relative humidity from Merlivat and Jouzel (1979)), then progressively removing small monthly rainfall amounts up to $20 \mathrm{~mm}$ (Table 2). It is clear that this selective removal of data at both Alice Springs and Perth has a dramatic effect on both the slopes and the intercepts of the LMWLs. The removal of D-excess values less than $3 \%$ in particular has the most dramatic effect, changing the slope of the LMWL for Alice Springs from 6.86 to 7.84 , and for Perth from 6.30 to 6.88. The progressive removal of rainfall amounts also has a variable effect. Removal of monthly totals up to $10 \mathrm{~mm}$ at Alice Springs increases the slope only slightly $(<1 \%)$ while progressive removal of small monthly amounts up to $20 \mathrm{~mm}$ at Perth continues to increase the slope of the LMWL from 6.88 to 7.60. This shows that using subjectively chosen cut-off values of rainfall amount or D-excess leads to a highly variable outcome. To do this effectively requires knowledge of local climate conditions. In contrast a PWLSR can be applied without local knowledge as a non-subjective approach to minimising the bias towards small events without a summary rejection of data which may be valid.

\subsection{Global GNIP stations}

Whilst for the Australian stations the slope of the PWLSR fitted line is larger than that of OLSR, this is not always the case for other sites in the GNIP network. For example the PWLSR $\left(\delta^{2} \mathrm{H}=5.72 \cdot \delta^{18} \mathrm{O}+2.24\right)$ for São Tomé (Fig. 4), which is located at latitude of $-3.24^{\circ}$ and longitude of $-15.31^{\circ}$ on a small island in the Atlantic Ocean, has a smaller slope than the OLSR $\left(\delta^{2} \mathrm{H}=6.31 \cdot \delta^{18} \mathrm{O}+5.27\right)$. In contrast, at Alice Springs (Fig. $2 \mathrm{~d}$ ) there is a clear depletion of $\delta^{18} \mathrm{O}$ with increasing rainfall amounts,

Table 2

OLSR parameters for D-excess $\geqslant 3 \%$ and varying monthly rainfall amounts from $\geqslant 0$ to $\geqslant 20 \mathrm{~mm}$ for Alice Springs and Perth.

\begin{tabular}{llllllll}
\hline \multirow{2}{*}{ Rainfall } & \multicolumn{2}{l}{ Alice Springs } & & \multicolumn{2}{l}{ Perth } \\
\cline { 2 - 3 } \cline { 6 - 7 } & $N$ & $a \pm \sigma_{a}$ & $b \pm \sigma_{b}$ & & $N$ & $a \pm \sigma_{a}$ & $b \pm \sigma_{b}$ \\
\hline$\geqslant 20 \mathrm{~mm}$ & 64 & $7.87 \pm 0.18$ & $12.3 \pm 1.2$ & & 187 & $7.60 \pm 0.24$ & $13.8 \pm 1.0$ \\
$\geqslant 10 \mathrm{~mm}$ & 82 & $7.91 \pm 0.17$ & $12.5 \pm 1.0$ & & 215 & $7.15 \pm 0.21$ & $11.6 \pm 0.9$ \\
$\geqslant 5 \mathrm{~mm}$ & 89 & $7.90 \pm 0.17$ & $12.1 \pm 1.0$ & & 228 & $6.92 \pm 0.19$ & $10.5 \pm 0.8$ \\
$>0 \mathrm{~mm}$ & 99 & $7.84 \pm 0.15$ & $11.5 \pm 0.9$ & & 239 & $6.88 \pm 0.18$ & $10.4 \pm 0.7$ \\
\hline
\end{tabular}

whereas, for São Tomé (which is closer to the moisture source region) the effect is not as pronounced, and in fact there are a number of large amount rainfall months that show little depletion in $\delta^{18} \mathrm{O}$ and have a low D-excess value. Such isotopic signatures have been observed in rainfall from the inner region of cyclones, which is considered the result of weak rainout effects and recharge from sea spray (Gedzelman et al., 2003; Fudeyasu et al., 2008), and at São Tomé these values are found during the local hurricane season from August to November (Landsea, 1991). Alice Springs on the other hand is located in the centre of Australia where heavy isotope depletion of the moisture is more likely, but also high temperature and low humidity may lead to enrichment of small rainfall amounts by re-evaporation below the cloud, and potentially evaporation of small rainfall amounts in the rain gauge prior to sampling.

The PWLSR method was applied to 288 stations in the GNIP data base with $N>36$ and the parameters for these stations as well as those with $N \leqslant 36$ are listed in the Supplementary data. Fig. 5 shows the geographical distribution of $\Delta a$. The mean change in slope, $\Delta a$, was 0.12 with 162 sites showing an increase in the slope or positive $\Delta a$ values, six sites showing no change and 120 sites having a decrease in slope or negative $\Delta a$. Of the sites with negative $\Delta a$ values two were significant at $95 \%$ confidence level, two were significant at $90 \%$ confidence level and four at $80 \%$ confidence level. Of the sites with positive $\Delta a$ values 19 were significant at $95 \%$ confidence level, 13 at $90 \%$ confidence level and 13 at $80 \%$ confidence level.

The complexity of the factors affecting the distribution of $\delta^{2} \mathrm{H}$ and $\delta^{18} \mathrm{O}$ in precipitation from site to site makes it difficult to fully analyse the $\Delta a$ distribution without the assistance of a Global Climate Model (GCM). Attempts to find distinct groupings of $\Delta a$ based on climate (Köppen-Geiger Climate Classification, Kottek et al., 2006) were of limited use. However, a few patterns can be discerned on a regional basis. Large positive values of $\Delta a$ tend to be found at sites with typical Mediterranean climates; hot dry summers and mild wet winters, where low D-excess for small rain events in summer have a dominant effect on the slope of the LMWL calculated using the OLSR method. Negative values of $\Delta a$ appear to be associated with first rainout at coastal or island sites, or small highly depleted precipitation amounts in cold climates. The decrease in slope observed when applying PWLSR to São Tomé is the result of high rainfall months with a low D-excess often with higher $\delta^{18} \mathrm{O}$ values than would be expected for heavy rainfall in a continental setting. Barbados is another location where this occurs. The effect of small amounts of depleted precipitation, mostly in winter, is seen at some sites in China, Canada and Europe. In some cases such as Hall Beach (N.W.T.), Canada, one extremely low D-excess value dominates the OSLR. Whilst the effect of evaporative fractionation during sampling or precipitation is generally considered more of an issue during warm weather, it clearly may also have an impact in cold conditions. Semi-arid and arid sites, like Alice Springs, where high evaporation rates were anticipated to result in highly positive $\Delta a$, in fact are not significantly different from the average.

Other possible factors such as sample size, $\delta^{2} \mathrm{H}$ and $\delta^{18} \mathrm{O}$ composition, latitude and normalised precipitation variability have been considered (Fig. 6). A moderate correlation was seen between the magnitude of the change in slope, $|\Delta a|$, and rainfall variability (Pearson correlation coefficient $r=0.41$ ). A weak correlation between $|\Delta a|$ and average $\delta^{2} \mathrm{H}$ and $\delta^{18} \mathrm{O}$ composition $(r=0.25)$, and very weak inverse correlation with period of record $(N)$ $(r=-0.18)$ were also observed. Whilst these correlations are weak some trends are obvious. The biggest change between the two calculated slopes is found at sites with a low number of samples (Fig. 6a). This may reflect the lack of a long term averaging effect, however, it is clear from Fig. $6 c$ that the longer term GNIP sites are predominantly from temperate mid-latitude zones particularly 
(a)

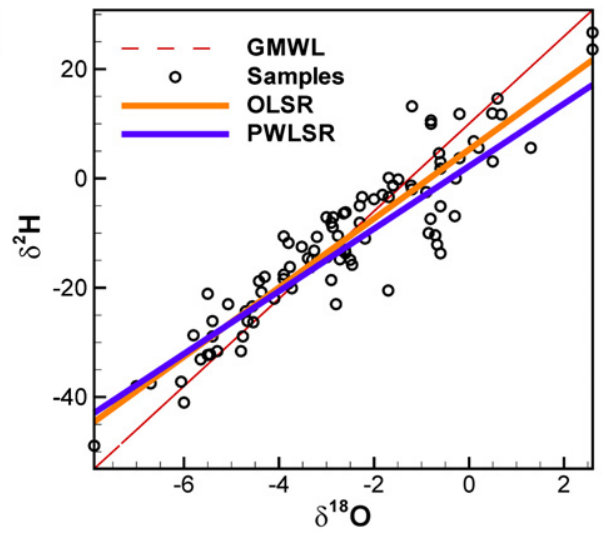

(c)

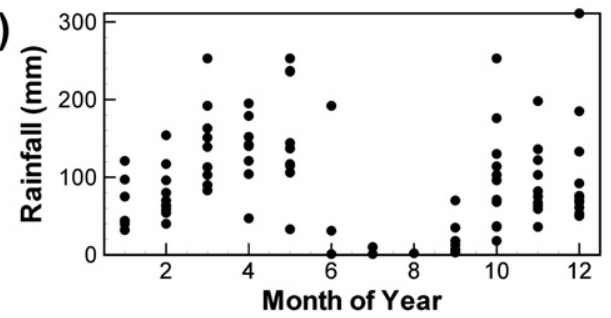

(b)

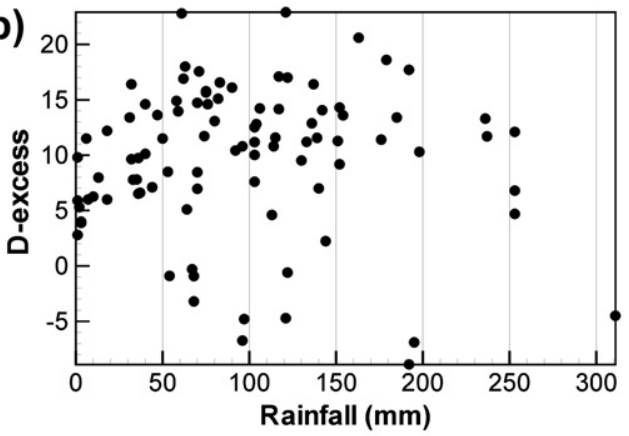

(d)

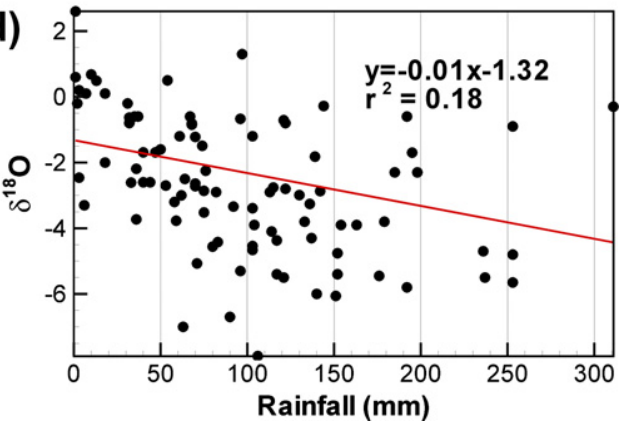

Fig. 4. São Tomé (Site $006193100 N=93$ ): (a) bivariate plot of $\delta^{2} \mathrm{H}$ against $\delta^{18} \mathrm{O}$ showing LMWL; (b) $\delta^{18} \mathrm{O}$ vs. rainfall amount; (c) sample rainfall amount by month; and (d) Dexcess against rainfall amount.

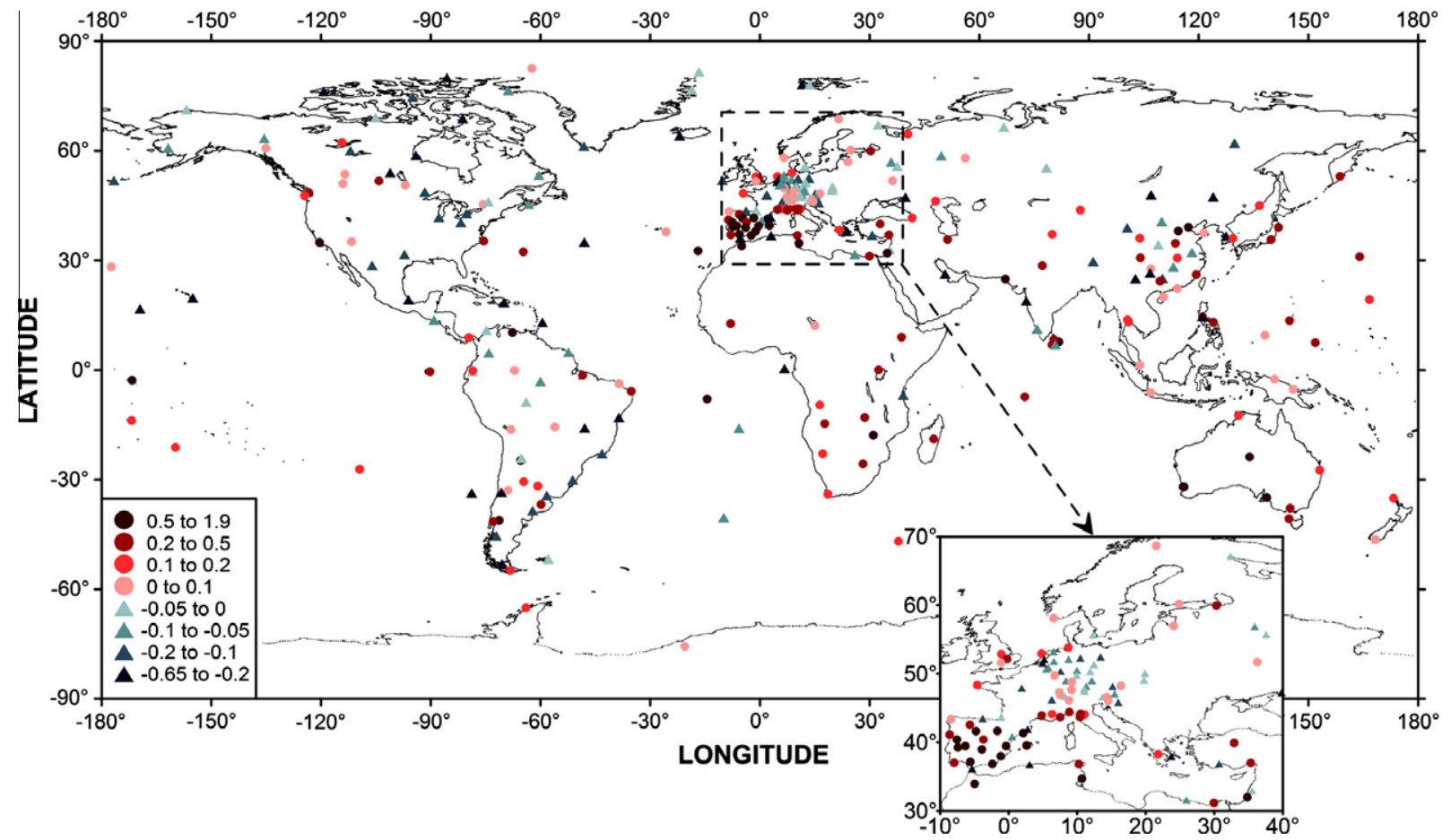

Fig. 5. Global plot of change in regression slope found when applying PWLSR instead of OLSR. Triangles represent a decrease in slope (e.g. Sao Tome) and circles an increase in slope (e.g. all Australian sites).

from a small area in Western Europe and fail to reflect the global variability in climate. We see clearly that the change between the two calculated slopes tends to be greater for sites where the weighted average $\delta^{2} \mathrm{H}$ and $\delta^{18} \mathrm{O}$ is more enriched, and also where the rainfall amount is more variable (Fig. $6 \mathrm{~b}$ and $\mathrm{d}$ ).

As humidity at the source of moisture is known to affect D-excess (Dansgaard, 1964), the relationship between $\Delta a$ and the monthly average relative humidity at each site was investigated
(Fig. 7). Because the GNIP data does not include vapour pressure for all sites, the long term average relative humidity has been calculated by taking the average of the long term (1968-1996) monthly mean relative humidity obtained from the NCEP/NCAR Reanalysis (Kalnay et al., 1996). Three main regions can be identified in Fig. 7; (a) sites with semi-arid and arid climates, (b) sites with Mediterranean climate, and (c) other sites. Aside from the clustering these three regions do not show any within-cluster relationship. 
(a)

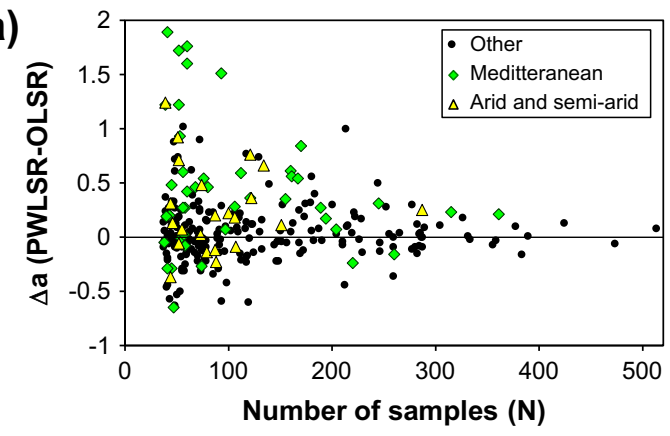

(c)

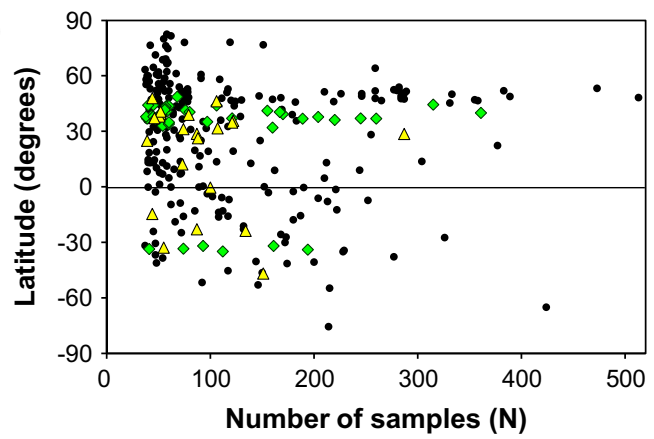

(b)

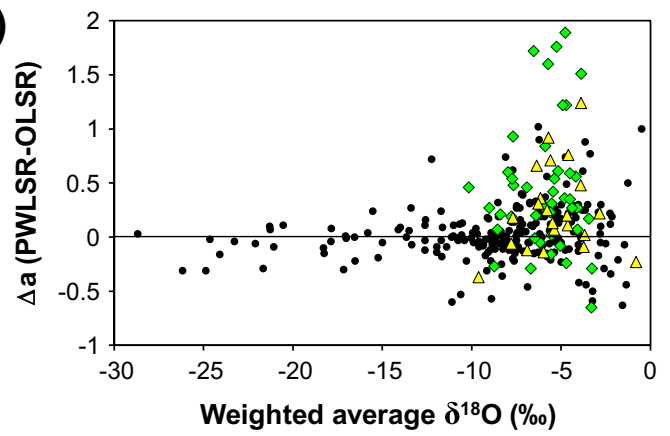

(d)

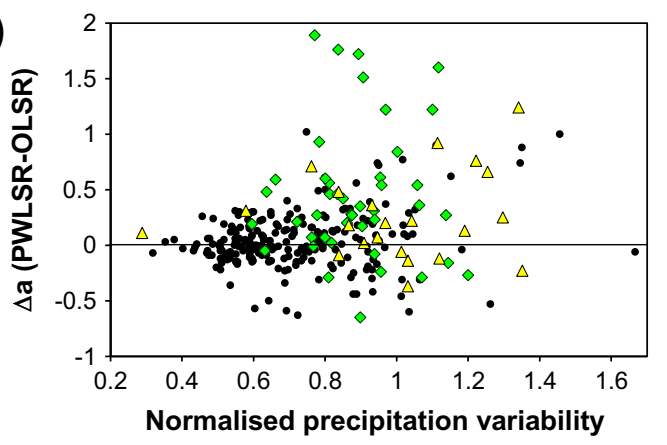

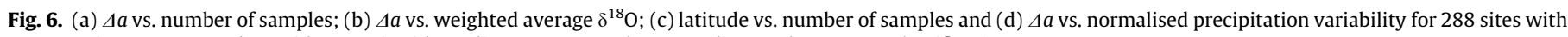
$N \geqslant 36$. Sites are grouped as arid or semi-arid, Mediterranean or other according to the Köppen classification.

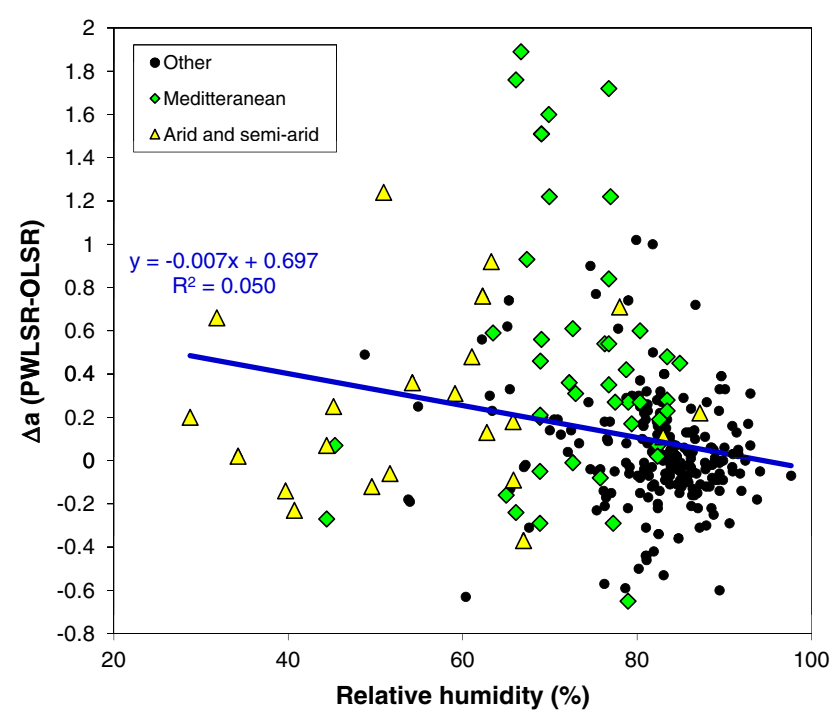

Fig. 7. Difference between the slope of OLSR and PWLSR $(\Delta a)$ against the relative humidity of the site. Sites are grouped as arid or semi-arid, Mediterranean or other according to the Köppen classification. Trend line shown is for all data.

However, overall a weak negative correlation $(r=-0.22)$ is seen between $\Delta a$ and relative humidity. Higher relative humidity at a location will result in less net evaporation and enrichment of falling raindrops (Stewart, 1975), and evaporative enrichment that does occur will follow a slope closer to the GMWL resulting in less change in D-excess (Gonfiantini, 1986). A better correlation may be expected if the humidity at the source of vapour was known.

\section{Conclusions}

Using a precipitation weighted analysis provides a non-subjective method for defining a LMWL which takes into account the significant influence of the rainfall amount on hydrological analyses, but allows for valid data with a low D-excess to still be included. Where the sampling methodology potentially allows some evaporation of small samples during collection the use of a PWLSR will minimise their impact. As it is difficult to determine whether sampling problems or meteorological processes are responsible for low D-excess in samples, we believe that using a PWLSR instead of an OLSR will result in improved LMWLs for hydrological applications at the majority of sites and that this method will assist those undertaking a broad study without local knowledge of meteorological or sampling conditions. It also provides a more robust alternative to the subjective removal of small rainfall amount or low Dexcess samples from the analysis. However, this method does not obviate the need for proper quality control during sampling, sample measurement and data management; nor does it reduce the value of undertaking a detailed isotope hydrology study of a site or region.

The use of a weighted approach is not applicable in all circumstances. In particular for those wishing to identify outliers or to estimate the value of, say $\delta^{2} \mathrm{H}$, when only $\delta^{18} \mathrm{O}$ has been measured, an unweighted regression may be more appropriate. For those investigating the interaction between hydrometeorological processes and stable isotope signatures in precipitation an unweighted regression is also likely to be of more value.

In Australia LMWLs calculated using a PWLSR have consistently higher slopes than using traditional techniques, and this paper presents new LMWL equations that are more useful than the existing equations when studying surface and groundwater hydrology in this region. Globally the effect of using a PWLSR is highly variable, however, its effect is most pronounced for Mediterranean climates where the most extreme effect of small precipitation events on the LWML is seen. Small amounts of depleted precipitation in cold climates may also have an undue impact on the LMWL which may be corrected using a PWLSR. Island and coastal sites where precipitation with a low D-excess may result from first rainout or tropical storms may also benefit from the use of the PWLSR. Overall, the complexity of the factors affecting the distribution of $\delta^{2} \mathrm{H}$ and 
$\delta^{18} \mathrm{O}$ in precipitation from site to site makes it difficult to fully analyse this distribution without the assistance of a Global Climate Model.

\section{Acknowledgements}

We would like to thank Roberto Gonfiantini, Suzanne Hollins and an anonymous reviewer for invaluable feedback which has greatly improved this manuscript. We also acknowledge the International Atomic Energy Agency for their ongoing maintenance of the Global Network of Isotopes in Precipitation.

\section{Appendix A. Supplementary data}

Supplementary data associated with this article can be found, in the online version, at http://dx.doi.org/10.1016/j.jhydrol.2012.07. 029.

\section{References}

Argiriou, A.A., Lykoudis, S., 2006. Isotopic composition of precipitation in Greece. J Hydrol. 327, 486-495.

Carr, J.R., 2012. Orthogonal regression: a teaching perspective. Internat. J. Math. Ed. Sci. Technol. 43 (1), 134-143.

Craig, H., 1961. Isotopic variation in meteoric waters. Science 133, 1702-1703.

Dansgaard, W. 1964. Stable isotopes in precipitation. Tellus 16, 436-368.

Fischer, M.J., Treble, P.C., 2008. Calibrating climate-180 regression models for the interpretation of high-resolution speleothem 180 time series. J. Geophys. Res. 113, D17103. http://dx.doi.org/10.1029/2007JD009694.

Fudeyasu, H., Ichiyanagi, K., Sugimoto, A., Yoshimura, K., Ueta, A., Yamanaka, M.D. Ozawa, K., 2008. Isotope ratios of precipitation and water vapor observed in Typhoon Shanshan. J. Geophys. Res. 113, D12113. http://dx.doi.org/10.1029/ 2007JD009313.

Gedzelman, S., Lawrence, J., Gamache, J., Black, M., Hindman, E., Black, R., Dunion, J., Willoughby, H., Zhang, X., 2003. Probing hurricanes with stable isotopes of rain and water vapor. Mon. Weather Rev. 131, 1112-1127.
Gonfiantini, R., 1986. Environmental isotopes in lake studies. In: Fritz, P., Fontes, J.Ch. (Eds.), Handbook of Environmental Isotope Geochemistry, vol. 3. Elsevier, New York, pp. 113-168.

Harvey, F.E., 2001. Use of NADP archive samples to determine the isotope composition of precipitation: characterizing the meteoric input function for use in ground water studies. Ground Water 39 (3), 380-390.

IAEA/WMO, 2006. Global Network of Isotopes in Precipitation. The GNIP Database. <http://www.iaea.org/water>.

IAEA, 1992. Statistical treatment of data on environmental isotopes in precipitation. Technical Report Series 331, IAEA Vienna, 781 pp.

Kalnay, E., Kanamutsu, M., Kistler, R., Collins, W., Deaven, D., Gandin, L., Iredell, M., Saha, S., White, G., Woollen, J., Zhu, Y., Leetmaa, A., Reynolds, R., Chelliah, M., Ebisuzaki, W., Higgins, W., Janowiak, J., Mo, K.C., Ropelewski, C., Wang, J., Jenne, R., Joseph, D., 1996. The NCEP/NCAR 40-Year Reanalysis Project. Bull. Amer. Meteor. Soc. 77, 437-471.

Kottek, M., Grieser, J., Beck, C., Rudole, B., Rubel, F., 2006. World Map of KöppenGeiger climate classification updated. Meteor. Z. 15, 259-263.

Landsea, C.W., 1991: West African Monsoonal Rainfall and Intense Hurricane Associations. M.S. Thesis, Dept. of Atmospheric Science, Colorado State University, Paper No. 484, 272 pp. <http://digitool.library.colostate.edu/// exlibris/dtl/d3_1/apache_media/ L2V4bGlicmlzL2R0bC9kM18xL2FwYWNoZV9tZWRpYS8yNzI3.pdf>.

Liu, J., Fu, G., Song, X., Charles, S.P., Zhang, Y., Han, D., Wang, S., 2010. Stable isotopic compositions in Australian precipitation. J. Geophys. Res. 115, D23307. http:// dx.doi.org/10.1029/2010JD014403.

Merlivat, L., Jouzel, J., 1979. Global climate interpretation of the Deuterium-Oxygen 18 relationship for precipitation. J. Geophys. Res. 84 (C8), 5029-5033.

Rozanski, K., Araguás-Araguás, L., Gonfiantini, R., 1993. Isotopic patterns in modern global precipitation. In: Swart, P.K., Lohmann, K.C., McKenzie, J., Savin, S. (Eds.), Climate Change in Continental Isotopic Records, Geophys. Monogr. Ser., 78, AGU, Washington, D.C., pp. 1-36.

Stewart, M.K., 1975. Stable isotope fractionation due to evaporation and isotope exchange of falling water drops: application to atmospheric processes and evaporation of lakes. J. Geophys. Res. 80, 1133-1146.

Treble, P.C., Budd, W.F., Hope, P.K., Rustomji, P.K., 2005. Synoptic-scale climate patterns associated with rainfall $\delta^{18} \mathrm{O}$ in southern Australia. J. Hydrol. 302, 270282.

Volk, W., 1958. Applied Statistics for Engineers. McGraw-Hill Book Company, Inc., New York 